\title{
(C) A METHOD FOR THE DETERMINATION OF NORADRENALINE AT NORMAL PLASMA LEVELS
}

\author{
by P. K. AMBLER* AND J. SPICER $\dagger$ \\ (From the Department of Clinical Chemistry, Auckland Hospital, Auckland, \\ New Zealand*, and the Institute for Social Research, University of Michigan, \\ Michigan, U.S.A.†)
}

(Accepted for publication February 18, 1980.)

\begin{abstract}
Summary. A detailed method for the determination of plasma levels of noradrenaline, involving adsorption on to an alumina column, elution and formation of the noradrenolutine, is described. Particulars are also given of the preparation of the alumina, the columns and the samples.
\end{abstract}

\section{INTRODUCTION}

Considerable evidence now indicates that individuals who exhibit certain psychological characteristics experience significantly increased risk of coronary heart disease (Jenkins, 1971 and Jenkins, 1976). The physiological and biochemical mechanisms by which this increased risk is mediated are little understood, though some promising directions for research are emerging (Dembroski, MacDougall and Shields, 1977). Of particular interest is the pathogenic potential of elevated catecholamine levels which may result in acute coronary events via such mechanisms as myocardial necrosis due to electrolyte imbalance, ventricular fibrillation or arterial spasm (Raab, 1966).

The plan of the experiment for which plasma catecholamine levels were required is recorded elsewhere (Spicer, unpublished data). An attempt was made to develop a method for determining plasma levels based on procedures reported by Renzini, Brunori and Valori (1970), Wood and Mainwaring-Burton (1975), Knight (1975) and Miura et al. (1977). Lack of sensitivity precluded the eventual measurement of adrenaline at normal plasma levels. Although this same problem affected assessment of noradrenaline levels below $1 \mathrm{nmol} / \mathrm{l}$, a workable method for measurement of this compound was achieved.

\section{MATERIALS AND METHODS}

Glass-distilled water deionised using Milli Q apparatus (Millipore Corp., Bedford, Massachusetts) was used for all solutions unless otherwise stated. The Milli $Q$ system was housed in a cool room at $4^{\circ}$ and a timer switch used to circulate the water for 3 min every hour. 
Before use, all glassware was acid-washed for at least $4 \mathrm{~h}$ in a $3 \mathrm{M}$ hydrochloric acid-nitric acid solution, then washed with both distilled and Milli $Q$ water. All reagents were of Analar grade.

(1) Perchloric acid as a $4 \mathrm{M}$ solution for protein precipitation.

(2) $5 \%$ di-sodium EDTA.

(3) $10 \%$ sodium metabisulphite $\mathrm{Na}_{2} \mathrm{~S}_{2} \mathrm{O}_{5}$.

(4) $2 \mathrm{M}$ hydrochloric acid made up in 1 litre lots for alumina preparation.

(5) Alumina (Merck)-standard grade.

(6) $0.02 \mathrm{M}$ acetic acid and $0.2 \mathrm{M}$ sodium acetate for alumina washing.

(7) Diphenol purple (ICN Pharmaceuticals) $0.025 \%$ in $50 \%$ ethanol.

(8) L-Noradrenaline (L-Arterenol) (Sigma Chemical Co.).

(9) $10 \mathrm{M}$ sodium hydroxide and $2.5 \mathrm{M}$ sodium carbonate made up in $500 \mathrm{ml}$ lots as required for $\mathrm{pH}$ adjustment. Solution $\mathrm{I}$ is also used for this purpose.

(10) $0.3 \mathrm{M}$ acetic acid in $500 \mathrm{ml}$ lots for use as an eluant.

(11) $0.002 \%$ cupric chloride $\mathrm{CuCl}_{2} 2 \mathrm{H}_{2} \mathrm{O}$.

(12) Ferricyanide/borate solution. $0.015 \%$ potassium ferricyanide dissolved in $3 \mathrm{M}$ sodium tetraborate, $\mathrm{Na}_{2} \mathrm{~B}_{4} \mathrm{O}_{7}$. Stable for one week stored in a dark bottle.

(13) $0.5 \%$ 2-mercaptoethanol (Merck). Prepared daily as a stock solution. From this a working solution of 2-mercaptoethanol and $10 \mathrm{M}$ sodium hydroxide in the ratio of $4: 1$ was prepared just prior to starting the fluorimetric reaction.

(14) Glacial acetic acid.

\section{Alumina preparation}

$500 \mathrm{~g}$ of alumina were washed at $80^{\circ}$ with $2 \mathrm{M}$ hydrochloric acid for $30 \mathrm{~min}$ using a plastic rod and winged stirrer to minimise colloid formation. A period of $30 \mathrm{~min}$ was allowed for the alumina to settle, the supernatant being discarded at the end of this time and the procedure repeated. This was followed by 10 min water washes and 5 min settling periods until the $\mathrm{pH}$ of the supernatant had reached 3.5 to 4.0. The alumina was then dried overnight in an oven at $100^{\circ}$ and activated at $300^{\circ}$ for $2 \mathrm{~h}$.

\section{Column preparation}

$11 \mathrm{~cm} \times 1.5 \mathrm{~cm}$ plastic test tubes (TVL) were used in a batch adsorption technique. $500 \mathrm{mg}$ of activated alumina were weighed into each and washed twice with $0.02 \mathrm{M}$ acetic acid, three times with water and four times with $0.2 \mathrm{M}$ sodium acetate, each wash lasting $5 \mathrm{~min}$. The purpose of this was to remove all extraneous fine particles of alumina which would otherwise cause interference in the blanks in the final reaction. The supernatant was discarded after every wash. Finally, $1 \mathrm{ml}$ each of $0.2 \mathrm{M}$ sodium acetate and $5 \%$ di-sodium EDTA plus $100 \mu \mathrm{l}$ of $0.25 \%$ diphenol purple was added to each tube. These were then capped and stored ready for use.

\section{Protein-free plasma preparation}

$7 \mathrm{ml}$ of $4 \mathrm{M}$ perchloric acid was added to approximately $35 \mathrm{ml}$ of reconstituted freeze-dried plasma. The mixture was stirred and centrifuged at $2000 \mathrm{rev} . / \mathrm{min}$ for $20 \mathrm{~min}$. The resulting supernatant was separated off, re-spun and the final liquid phase stored at $4^{\circ}$. Further precipitation of fine colloidal particles may occur at this temperature, so it is preferable to re-centrifuge rather than incur interference in the final stages of analysis.

Freeze-dried plasma is prepared from blood collected in glass tubes containing no anti-oxidant. As these conditions are conducive to fast noradrenaline decay, the level of noradrenaline in the freeze-dried plasma, and hence the protein-free phase, was considered to be zero.

\section{Sample collection}

$30 \mathrm{ml}$ of blood were collected and immediately divided into three $10 \mathrm{ml}$ aliquots which were placed in separate $100 \mathrm{~mm} \times 17 \mathrm{~mm} \mathrm{S4T} \mathrm{plastic} \mathrm{tubes} \mathrm{(Lab.} \mathrm{Services,} \mathrm{Auckland)} \mathrm{containing} 0.3 \mathrm{ml}$ of $10 \%$ sodium metabisulphite and $0.3 \mathrm{ml}$ of $5 \%$ di-sodium EDTA. Each tube was capped, mixed by inversion and placed in an ice-bath until centrifugation. 
The specimens were spun within $5 \mathrm{~min}$ and the plasma transferred to another tube containing $1 \mathrm{ml}$ of $4 \mathrm{M}$ perchloric acid. The mixture was vortex mixed, centrifuged at $2000 \mathrm{rev} . / \mathrm{min}$ for $10 \mathrm{~min}$ and the resulting supernatant re-spun. The clear protein-free phase was frozen and stored for no more than $24 \mathrm{~h}$ before analysis.

\section{Standard preparation}

(1) Stock solution: $50 \mathrm{mg}$ of L-noradrenaline were dissolved in protein-free plasma and made up to $100 \mathrm{ml}$. Stored at $-20^{\circ}$ this is stable for at least 3 months.

(2) Standard solutions: $0.1 \mathrm{ml}$ of stock was diluted to $100 \mathrm{ml}$ with protein-free plasma. 100,50 and $25 \mu \mathrm{l}$ of this solution were each diluted to $25 \mathrm{ml}$ and a $25 \mu \mathrm{l}$ to $50 \mathrm{ml}$ dilution was also made. These four solutions are equivalent to $11.83,5.91,2.96$ and $1.48 \mathrm{nmoles} / 1(2,1,0.5$ and $0.25 \mathrm{ng} / \mathrm{ml})$ and were prepared fresh on the day of analysis.

\section{Adsorption and elution}

$5 \mathrm{ml}$ of specimen were added to the prepared adsorption tubes. The $\mathrm{pH}$ at which catecholamines are at their greatest percentage adsorption on alumina is 8.4 and alteration of the mixture to this was made by addition of $10 \mathrm{M}$ sodium hydroxide with final adjustment being done with $2.5 \mathrm{M}$ sodium carbonate or $4 \mathrm{M}$ perchloric acid. At this point, the indicator colour should be just purple and should remain so on shaking. Mixing was carried out for $5 \mathrm{~min}$ on a rotary Matburn mixer after which the alumina was allowed to settle for about $30 \mathrm{sec}$ and the supernatant aspirated off. Two successive washes with $0.2 \mathrm{M}$ sodium acetate $(10 \mathrm{ml})$ and another two using $10 \mathrm{ml}$ of Milli $\mathrm{Q}$ water were carried out. After the final water wash the alumina was decanted as a suspension into $0.7 \mathrm{~cm} \times 4 \mathrm{~cm}$ polythene columns (Bio-Rad) fitted with a polyethylene sinter and a $10 \mathrm{ml}$ reservoir. Vortex washing of the tubes with water removed the remaining alumina.

The columns were drained using suction and centrifugation and the bottoms capped. $1 \mathrm{ml}$ of $0.3 \mathrm{M}$ acetic acid was added to the column, the top sealed with parafilm "M" (American Can $\mathrm{Co}$.) and the whole vortexed for about $5 \mathrm{sec}$ to obtain uniform dispersion. The columns were then rotary-mixed for 5 $\mathrm{min}$, the tops and bottoms removed and the eluate centrifuged into $100 \mathrm{~mm} \times 17 \mathrm{~mm}$ S4T plastic tubes (Lab. Services Auckland) containing $0.1 \mathrm{ml} 5 \%$ di-sodium EDTA. These solutions are reported to be stable for up to 2 weeks at $4^{\circ}$ (Renzini et al., 1970).

To remove any colloidal alumina which may have passed through the sinters it was necessary to filter these solutions. Each solution was sucked into a $2 \mathrm{ml}$ Summit syringe using a Terumo $25 \mathrm{Gl}$ disposable needle. The solution was then filtered through a $0.22 \mu$ Millex filter (Millipore Corp.) into a $77 \mathrm{~mm} \times 12 \mathrm{~mm} \mathrm{S3T}$ tube (Lab. Services).

\section{Fluorimetric reaction}

All volumes were measured using Oxford micropipettes.

$200 \mu \mathrm{l}$ from each noradrenaline solution was added to two acid-washed Brown cuvettes containing $10 \mu \mathrm{l}$ of $0.002 \%$ cupric chloride solution, one to be used as the test and the other as its corresponding blank.

(a) Test reaction: $370 \mu \mathrm{l}$ of $0.15 \%$ potassium ferricyanide solution was added at the start of the time-reaction. This brought the solution to $\mathrm{pH} 6.5$ at which oxidation of noradrenaline is favoured (Laverty and Taylor, 1968). After $3 \mathrm{~min} 125 \mu \mathrm{l}$ of the 2-mercaptoethanol/sodium hydroxide solution was added followed $5 \mathrm{~min}$ later by $20 \mu \mathrm{l}$ of glacial acetic acid. The solution was vortex-mixed after each addition.

(b) Blank reaction: A faded blank was prepared by adding $25 \mu \mathrm{l}$ of $10 \mathrm{M}$ sodium hydroxide $3 \mathrm{~min}$ after the ferricyanide solution. A $10 \mathrm{~min}$ interval was allowed to elapse after which time $100 \mu \mathrm{l}$ of water followed immediately by $20 \mu \mathrm{l}$ of glacial acetic acid were added.

Both solutions are quite stable at $4^{\circ}$.

The solutions were read fluorimetrically at excitation and emission wavelengths of $430 \mathrm{~nm}$ and 500 $\mathrm{nm}$, respectively. Measurements were made using an Aminco-Bowman spectrofluorimeter fitted with a xenon lamp and a R136 photomultiplier. Mirrors and $1 \mathrm{~mm}$ slits were placed in the cell housing. The Brown cuvettes were blanked against a $5 \mathrm{cc}$ quartz cuvette. 


\section{RESULTS AND DISCUSSION}

The method uses the principle outlined by Laverty and Taylor (1968) for the specific oxidation of noradrenaline at $\mathrm{pH}$ 6.5. Interference from plasma adrenaline levels at this $\mathrm{pH}$ is approximately $3 \%$ (Diamant and Byers, 1975) and is considered to be negligible.

The accuracy of the method is dependent on systematic losses and experimental error. It is essential that the time at which noradrenaline is at $\mathrm{pH} 8.4$ is kept to a minimum. Although this is the $\mathrm{pH}$ at which catecholamines are best adsorbed on to alumina, it is also known that they auto-oxidise rapidly under alkaline conditions (Weil-Malherbe, 1968). The presence of di-sodium EDTA in the columns slowed this process allowing thorough washing of the alumina before elution. If two water washes were not used fluctuation in $\mathrm{pH}$ was found on addition of the $0.3 \mathrm{M}$ acetic acid giving a variation in percentage elution. In the method described the only variable error to this point was the amount of alumina lost in transfer between the tubes and the columns and this was kept to a minimum by water vortexing.

Renzini et al. (1970) suggested the addition of di-sodium EDTA stabilised the eluate for 2 weeks at $4^{\circ}$. The addition was made but, as no indication was given as to the stability at room temperature of the solution, it was considered necessary to assay it as quickly as possible.

Removal of the colloidal alumina gave volume loss problems. Firstly, the syringe failed to pick up all the eluant and, secondly, there was a 10\% loss in the filtering apparatus. Although this caused no error in the quantitation procedure, it limited the assay to only one set of test/blank specimens per sample. Increase in the amount of eluant only decreased the concentration of catecholamines, and the eluant concentration used, namely $0.3 \mathrm{M}$, gave the maximum percentage elution. This was consistent with the findings of Wood and Mainwaring-Burton (1975) and Knight (1975).

The method of analysis using the ferricyanide oxidation to noradrenolutine was based on procedures outlined by Renzini et al. (1970) and Wood and Mainwaring-Burton (1975). 2-mercaptoethanol was used as the stabilising agent under alkaline conditions because it gave low blanks, was cheaper than related mercapto-stabilising agents and gave no interaction with cupric ions, the catalyst in the oxidising step. Combined addition of 2-mercaptoethanol and sodium hydroxide has long been known to give increased fluorescence (Weil-Malherbe, 1968). By bringing the final $\mathrm{pH}$ of the solution to $\mathrm{pH} 5.3$ with glacial acetic acid, the authors produced very stable conditions in which no fluorescence loss was noted over $24 \mathrm{~h}$. No precipitation of cupric compounds occurred.

The major problem at the analysis stage was the matching of the Brown cuvettes. Because of the low sensitivity at low levels, any scratch marks on the cuvette caused variations in the galvanometer readings. Cleanliness of the cuvettes was also of maximum importance. With a matched set of acid-washed cuvettes the authors achieved a precision of $\pm 6 \%$ including galvanometer error over a range of $1 \mathrm{nmol} / \mathrm{l}$ to a $10 \mathrm{nmol} / \mathrm{l}$, the range over which linearity of readings was also achieved. The limit of sensitivity was taken to be that fluorescence which was 
twice that of the blank, and this occurred in the region of $1 \mathrm{nmol} / \mathrm{l}$. This is below the normal range of $1.8-4.1 \mathrm{nmol} / /$ for noradrenaline.

Interference from other substances structurally related to catecholamines can affect the specificity of the results. Normetanephrine and metanephrine are not adsorbed on to alumina and will therefore not interfere with this method. Other chemically related compounds such as dopamine, tyrosine and their structural cousins do not, in the main, form compounds which fluoresce at wavelengths near $500 \mathrm{~nm}$ when oxidised below $\mathrm{pH} \mathrm{7.} \mathrm{The} \mathrm{only} \mathrm{interfering} \mathrm{compounds} \mathrm{are}$ $\alpha$-methylnoradrenaline which produces minimal fluorescence and $\mathrm{L}$-dopa which causes major interference.

The maximum number of specimens which could be processed in a day from adsorption to final calculation was 12 . This does not include the time involved in preparation of alumina and columns for which at least one day must be set aside.

\section{REFERENCES}

Dembroski, T. M., MacDougall, J. M., and SHIELDS, J. L. (1977): 'Physiological reactions to social challenge in persons evidencing the Type A coronary-prone behaviour pattern.' J. Hum. Stress, 3 (3), 2.

DiAmANT, J., and BYERS, S. O. (1975): “A precise catecholamine assay for small plasma samples.' J. Lab. Clin. Med., 85, 678.

JENKINS, C. D. (1971): 'Psychologic and social precursors of coronary disease.' New Eng. J. Med., 284, 244.

JENKINS, C. D. (1976): 'Recent evidence supporting psychologic and social risk factors for coronary disease.' New Eng. J. Med., 294, 987.

KNIGHT, L. G. (1975): 'Effects of compression on plasma catecholamines and lipids.': M.Sc. Thesis, University of Auckland, Auckland.

LAVERTY, R., and TAYLOR, K. M. (1968): 'The fluorimetric assay of catecholamines and related compounds.' Anal. Biochem., 22, 269.
Miura, Y., Campese, V., Dequattro, V., and MEIJER, D. (1977): 'Plasma catecholamines via an improved fluorimetric assay: comparison with an enzymatic method.' J. Lab. Clin. Med., 89, 421.

RAAB, W. (1966): 'Emotional and sensory stress factors in myocardial pathology.' Am. Heart $J ., 72,538$.

Renzini, V., Brunori, C. A., and Valori, C. (1970): 'A sensitive and specific fluorimetric method for the determination of noradrenaline and adrenaline in human plasma.' Clin. Chim. Acta, 30, 587.

WEIL-M ALHERBE, H. (1968): " The estimation of total catecholamines and some catecholamine metabolites in human urine." Methods of Biochemical Analysis, Interscience publishers, New York, Vol. 16, p. 293.

WOOD, W. G., and Mainwaring-Burton, R. W. (1975): 'The development and evaluation of a semi-automated assay for catecholamines suitable for plasma and urine.' Clin. Chim. Acta, 61, 297. 
Copyright of Australian Journal of Experimental Biology \& Medical Science is the property of Blackwell Publishing Limited and its content may not be copied or emailed to multiple sites or posted to a listserv without the copyright holder's express written permission. However, users may print, download, or email articles for individual use. 